\title{
El análisis arqueológico-urbanístico: una metodología integral para el estudio de la primera Ciudad de México
}

\author{
Archaeological-Urban Planning Analysis: A Method for the Study \\ of the First Mexico City
}

\author{
RODRIGO OCTAVIO TIRADO DE SALAZAR \\ Escuela Nacional de Antropología e Historia, México \\ rodrigotisa@gmail.com
}

\begin{abstract}
Resumen: Ya desde sus orígenes, la Ciudad de México se presenta como una urbe complicada y yuxtapuesta: una ciudad europea edificada sobre la prehispánica Tenochtitlan. Así, considerando sobre todo su dimensión occidental, la tendencia general de las investigaciones urbanísticas sobre la primera Ciudad de México ha sido, hasta este momento, indagar los paradigmas urbanos del Renacimiento o de la Antigüedad clásica en busca de una explicación para su traza. Tras un análisis exhaustivo de la trama urbana de la Ciudad de México, el presente trabajo pretende, por una parte, romper con los estereotipos y desentrañar las estructuras urbanas antiguas, probar que estas fueron reflejos directos de la realidad de los primeros conquistadores que planearon la ciudad (con un horizonte cultural imbuido del mundo islámico medieval que tanto permeó en la península ibérica) y, por la otra, mediante un el ejemplo práctico del establecimiento del límite norte de la primera Ciudad de México, establecer la utilidad de una metodología interdisciplinar basada en la integración de diversas disciplinas como la historia, el urbanismo y la arqueología, para acercarse de manera más global y precisa a los fenómenos urbanos y sus sustratos históricos y culturales.
\end{abstract}

Palabras clave: urbanismo americano, conquista, colonia, Ciudad de México, urbanismo medieval, urbanismo islámico, metodología urbana, estudios interdisciplinares, Nueva España, Hernán Cortés, Alonso García Bravo.

Abstract: Since its origins, Mexico City is presented as a complicated and juxtaposed city: a European city built on the pre-Hispanic Tenochtitlan. Thus, it was always concentrating on its western dimension, the general trend of urban research on the very first Mexico City has been, until now, to investigate the urban paradigms of the Renaissance or Classical antiquity in search of an explanation for its trace. On the one hand, after an exhaustive analysis of the urban fabric of Mexico City, the present work intendsto break stereotypes and unravel ancient urban structures, proving that these were direct reflections of the reality of the conquerors who planned the city (with a cultural horizon imbued with the

Recibido: 7 de marzo de 2019 aceptado: 25 de noviembre de 2019; publicado: 31 de marzo de 2020.

Revista Historia Autónoma, 16 (2020), pp.123-138

e-ISSN: 2254-8726; https://doi.org/10.15366/rha2020.16.007 
medieval Islamic world that permeated so deeply in the Iberian Peninsula).On the other hand, through a practical example of the establishment of the northern limit of the first Mexico City, to set the usefulness of an interdisciplinary methodology based on the integration of various disciplines such as history, urban planning and archeology, to approach urban phenomena and their historical and cultural substrates in a more globally and precisely way.

Keywords: American urbanism, conquest, colonial period, Mexico City, medieval urbanism, Islamic urbanism, urban methodology, interdisciplinary studies, New Spain, Hernán Cortés, Alonso García Bravo.

\section{Introducción}

La Ciudad de México se presenta como un objeto de estudio que se desborda tanto en tamaño como en posibles enfoques, dada su importancia y su riqueza histórico-social. Y aunque, por un lado, es verdad que se han emprendido diversos análisis sobre dicha ciudad, es cierto a su vez que estos han sido llevados a cabo desde una óptica tradicional, alejada de la interdisciplinariedad y dejando casi siempre de lado el primer trazado urbano.

El acercamiento inter y transdisciplinar se refiere al desarrollo de una metodología ecléctica que tome los rasgos más relevantes de diversas disciplinas como son la historia (análisis documental y cartográfico), la arquitectura (análisis estructural), la arqueología (análisis estratigráfico), el urbanismo (análisis urbano) y herramientas como los Sistemas de Información Geográfica (SIG). Haciendo uso de todos estos instrumentos teóricos y metodológicos, podremos acercarnos a la vastedad de la capital mexicana e iniciar una comparación con distintas ciudades de la península ibérica (en particular, aquellas habitadas por los conquistadores), de forma que salga a la luz el grado en el que los geómetras recién llegados a tierras americanas hicieron uso de sus propios referentes en la planeación de la primera Ciudad de México.

Nuestro interés, entonces, se centra en los orígenes e influencias urbanas de la primera trama de la urbe que se erguiría como la capital de la Nueva España. Antes de postular nuestras propias conclusiones, quisiéramos, sin embargo, hacer un breve recorrido por las teorías que nos precedieron, de manera que sea posible ponderar sus elementos valiosos, por una parte y, por la otra, refutar ciertas partes que podrían antojársenos excesivas.

Para comenzar, mencionaremos la teoría que postula un origen absolutamente renacentista para el trazado de la urbe que nos concierne ${ }^{1}$, que, aunque se ha ido rezagando con el tiempo, aún conserva alguna validez para cierto número de investigadores.

\footnotetext{
${ }^{1}$ Stanislawski, Dan, "Early Spanish Town Planning in the New World”, en Geographical Review, vol. 37, 1 (1947), pp. 94-105. https://doi.org/10.2307/211364

Valero de García, Ana Rita, La ciudad de México-Tenochtitlán, su primera traza (1524-1534), México, Jus, 1991.
} 
No obstante, son los postulados con una cualidad más orgánica, que atribuyen la fuente del primer diseño de la Ciudad de México a una fusión de la influencia de los modelos peninsulares y el trazado de la ciudad prehispánica subyacente, los cuales llevan la delantera en la actualidad. Sin embargo, estas teorías todavía tienen camino por recorrer y deben alcanzar una mayor precisión, pues frecuentemente se han basado en la existencia de un supuesto "urbanismo cristiano", derivado del urbanismo grecorromano, que habría trasplantado sus características de forma directa al continente americano.

Por esta razón, en el transcurso de mis estudios, he decidido ampliar la concepción del urbanismo peninsular y pasar de un urbanismo cristiano y grecolatino al estudio de la posibilidad de que la configuración urbana proveniente de la península ibérica en el siglo XVI conste a su vez de otros elementos no necesariamente de orígenes clásicos $-\mathrm{o}$, al menos, no en su totalidad-, sino que se trate, probablemente, de un híbrido íntimamente relacionado con el urbanismo islámico medieval.

La presencia del componente islámico resulta mucho más plausible si se ponderan las distancias tanto geográficas como culturales que se abrían entre los conquistadores castellanos y los tratadistas del urbanismo renacentista. En adición, debemos tener en cuenta que dichos conquistadores no contaban con una formación elitista y que las últimas tendencias urbanísticas muy probablemente no se encontraban al alcance de personajes como Alonso García Bravo y Hernán Cortés, quienes, a pesar de posiblemente haber sido instruidos en la Universidad de Salamanca ${ }^{2}$, nacieron en el último periodo de lo que conocemos como Edad Media y poseían un imaginario estructurado acorde con los paisajes en los que se desarrollaron, los viajes que emprendieron y las urbes que mejor conocían.

Por añadidura, cabe mencionar que la conquista de Granada, guerra en la que participó el padre de Hernán Cortés ${ }^{3}$, se ha pasado por alto al establecer el marco teórico y cultural del conquistador de México; sin embargo, dicho evento histórico resulta trascendente de dos maneras: en primer término, debemos recordar que la identidad española se forma sobre la base de la negación de lo islámico; en segundo, debemos considerar que, en el marco conceptual de Cortés la cultura islámica será vista como el paradigma principal de la otredad, su representante, y es por ello que en su "Segunda carta de relación”, el conquistador describe los templos mexicas llamándolos "mezquitas" 4.

En estas circunstancias, no resulta de ninguna manera descabellado afirmar que el modelo islámico se encontraba grabado en la mentalidad de los conquistadores y contribuía a conformar su cosmovisión gracias al inmenso influjo que esta cultura ejerció en la realidad de la península.

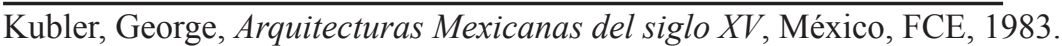

Tovar de Teresa, Guillermo, La ciudad de México y la utopía en el siglo XVI, México, Seguros de México, 1987.

${ }^{2}$ Martínez, José Luis, Hernán Cortés: versión abreviada, México, FCE, 1992.

Duverger, Christian, Cortés. La biografía más reveladora, Ciudad de México, Santillana, 2005.

${ }^{3}$ Ibídem, pp. 35-43.

${ }^{4}$ Cortés, Hernán, Cartas y relaciones de Hernán Cortés al Emperador Carlos V, París, central de los Ferro-Carriles

A. Chaix y ca., 1866, p. 72. 
Muestra de ello es que numerosas urbes medievales españolas — gran cantidad de ellas de fundación islámica - poseen rasgos comparables a los del primer trazado de la Ciudad de México. De igual forma, algunas de las estrategias defensivas de Hernán Cortés son rastreables hasta estas ciudades de la metrópoli. Aquí surge una pregunta que resulta esencial para nosotros: ¿los elementos urbanísticos de influencia islámica encontrados en la Ciudad de México persisten idénticos a los encontrados en las ciudades peninsulares o el nuevo entorno y la ciudad prehispánica preexistente demandan de ellos ciertas adaptaciones?

Es pertinente señalar que una característica central del urbanismo islámico reside en el alto nivel de adaptación de la urbe a su entorno y en la reutilización de las estructuras urbanas precedentes.

Cronológicamente, nuestro análisis se enmarca en el periodo en el que se estableció la primera Ciudad de México española, planeada por el geómetra Alonso García Bravo y encomendada por el mismo Hernán Cortés. Esta primera urbe fue levantada tras la destrucción o gran modificación de la ciudad precolombina de Tenochtitlan y fue terminada en $1524^{5}$, año que representa nuestro límite temporal mínimo.

Por otra parte, la urbe mantiene esta estructura hasta el momento de la llegada del primer virrey de Nueva España, don Antonio de Mendoza, en el año de $1535^{6}$, que porta consigo un ejemplar del pensamiento del arquitecto renacentista Juan Bautista Alberti. Así, fue el primer virrey quien se consagró a la reestructuración de la urbe para otorgarle un aspecto más renacentista. Por esta razón, he situado el límite temporal máximo de la investigación en ese mismo año.

Una vez señalados los límites temporales, convendría establecer las acotaciones geográficas específicas, ya que el área que alcanza actualmente la Ciudad de México difiere enormemente de aquella trazada por Alonso García Bravo, ya que la megalópolis se ha extendido hasta comprender poblaciones que en el siglo XVI eran completamente ajenas. Se puede afirmar sin temor a grandes márgenes de error que la primera urbe trazada por el geómetra se encuentra enmarcada dentro de la actual delegación Cuauhtémoc y que se circunscribe — a muy grandes rasgos - al entorno más apegado al actual centro de la ciudad.

Además de los límites cronológicos y espaciales, se impone una tercera línea de acotación para nuestro estudio: la demarcación cultural. Esta hace que nuestra aproximación se ciña a la ciudad castellana, dejando de lado el trazado de la ciudad prehispánica y sus alrededores, cuya división en cuatro barrios indígenas se encontraba para esos años probablemente intacta ${ }^{7}$. El urbanismo precolombino rebasa la problemática de nuestro análisis, que tiene como marco, como hemos mencionado antes, el horizonte teórico y cultural de los conquistadores al trazar

\footnotetext{
${ }^{5}$ Valero de García, Ana Rita, La ciudad de México-Tenochtitlán... op. cit., pp. 79-80.

${ }^{6}$ Martínez, José Luis, Hernán Cortés... op. cit.

Duverger, Christian, Cortés, la biografía... op. cit., p. 331.

${ }^{7}$ Caso, Alfonso, "Los barrios antiguos de Tenochtitlan y Tlatelolco", en Memorias de la Academia Mexicana de la Historia, 15 (1956), p. 10.
} 
la primera Ciudad de México española y hasta qué punto este horizonte está fusionado con el urbanismo islámico.

En cuanto a la novedad y el provecho de la metodología que utilizamos, es oportuno especificar que el empleo del registro arqueológico como fuente de datos que corroboran las informaciones obtenidas en fuentes históricas o cartográficas nos permite alcanzar cierta seguridad tanto cuantitativa como cualitativa en cuanto a la naturaleza de lo que se encontraba dispuesto en un sector de la urbe, así como de los distintos eventos a los que estuvo expuesto a lo largo de los años. De la misma manera, nos permite observar los diferentes métodos manejados por los ingenieros de esa época para respaldar el terreno y establecer un marco comparativo que compruebe la homogeneidad o heterogeneidad de estas técnicas.

En adición, no se puede ignorar el beneficio que supone el uso de la arqueología en la delimitación de la ciudad española, ya que es esta disciplina la que nos informará de los enclaves precisos de edificaciones prehispánicas entrado ya el siglo XVI y de la localización de las primeras construcciones novohispanas.

Sin embargo, en cuanto a las consideraciones arqueológicas, se debe aclarar que el estudio de las cerámicas provenientes de la península ibérica en la Ciudad de México ha sido muy descuidado y este hecho complica la datación de los primeros periodos coloniales y de la convivencia de cerámica Azteca IV, Azteca V y Colonial. Conjuntamente, se da el inconveniente de una clasificación de la cerámica llamada Colonial realizada muy grosso modo, ya que abarca toda la cerámica no prehispánica; esta clasificación, proveniente del ámbito estadounidense, resulta francamente insuficiente ${ }^{8}$.

Aun así, resulta de particular relevancia la inclusión de los estudios arqueológicos más centrados en las excavaciones que en los análisis cerámicos por las razones que hemos expuesto-, ya que los estudios previos no habían comprendido estos aspectos metodológicos y se habían basado exclusivamente en la cartografía antigua y en los datos históricos.

El enfoque de nuestro análisis se sustenta en la convicción de que las explicaciones más cercanas a la verdad suelen producirse por medio de distintos puntos de vista y desde diferentes disciplinas que terminan por resultar complementarias en sus metodologías; es decir, nos parece relevante la comprensión de que una urbe requiere de un enfoque múltiple que fusione distintos resultados específicos en una visión más compleja y cercana a la realidad.

Los estudios urbanísticos interdisciplinares no han sido, hasta ahora, la costumbre. En este artículo se propone una metodología para el análisis de ciudades antiguas que involucra documentos históricos, cartografías antiguas y contemporáneas (que arrojan en su traza la evolución de determinados rasgos encontrados en la Antigüedad y, por lo tanto, confirman su presencia) y el estudio de las excavaciones arqueológicas practicadas dentro del espacio urbano.

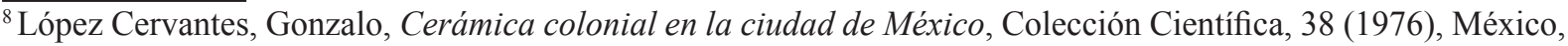
INAH.
} 


\section{Metodología}

Una metodología clara, proveniente de una concepción precisa del objeto de estudio y de un adecuado planteamiento del problema, resulta cardinal en el desarrollo de una investigación.

Cuando se realizan análisis bibliográficos, es necesario distinguir entre fuentes primarias, secundarias y análisis dedicados a la primera Ciudad de México. Las fuentes son de particular utilidad en cuanto a que contribuyen a la localización de elementos y características derivados de su lectura. En cuanto a las investigaciones anteriores sobre la trama de la Ciudad de México, una depuración y corroboración previa de los datos resulta necesaria.

Los datos cartográficos, por otra parte, servirán para localizar y discernir la evolución que los distintos elementos de la ciudad cortesiana han presentado a través de los años.

En cuanto a las fuentes arqueológicas, como ya he detallado con anterioridad, nos servirán para ratificar la información que conseguiremos por medio de los demás métodos analíticos, ya que constituyen una herramienta que no está sujeta a la ideología del momento y no se puede falsear, siempre y cuando la excavación se haya llevado a cabo con cierto rigor.

Una vez especificados los elementos que entran en juego en nuestra metodología, procederé a detallarla paso a paso:

1.- El análisis de la Ciudad de México parte de la observación del callejero actual de la urbe, en el cual se delimita el espacio que será analizado. Esto significa delinear la ciudad española y los barrios indios que la rodeaban o, por lo menos, hacer un intento de delimitación tan ajustado a la realidad como sea posible.

2.- Una vez que se ha marcado el espacio que será analizado, es necesario localizar las vías de comunicación originales que nos serán aportadas por medio de las cartografías antiguas. En caso de no contar con ellas, es viable concebir una distinción tentativa de los tipos de vías por medio de los destinos hacia donde se dirigían y el grado de plasticidad de la vía. Una vía antigua, por ejemplo, presentará un trazado más orgánico o sinuoso que una vía trazada recientemente.

3.- Enseguida es importante observar nuevamente el callejero actual y, específicamente, el trazado de las calles, para diferenciar entre ellas propensiones y, de cierta manera, "unidades cartográficas", como se hace en un análisis de paramentos utilizando el método Harris, pero, en este caso, aplicando la técnica a la planimetría actual de la ciudad. La localización de unidades cartográficas es fundamental para poder ver el nivel de relación que existe entre ellas y así poder comprender si la unidad es antigua o no.

4.- El paso sucesivo consiste en realizar una selección de los edificios o componentes urbanos que resultan fundamentales dentro de ese espacio y que aparecen en o están 
relacionados con las cartografías antiguas. En otras palabras, hay que distinguir ciertos elementos que serán los pilares del análisis urbanístico. Algunos ejemplos de la primera Ciudad de México los constituyen las calzadas prehispánicas, el trazado de las calles, el edificio de las Atarazanas, las Casas Viejas de Cortés o el mismo emplazamiento de la ciudad con respecto a la laguna de México.

5.- En el transcurso del análisis es necesario observar la forma en la que las unidades cartográficas reaccionan y se comportan con respecto a los elementos específicos que he mencionado más arriba. Por otro lado, también hay que considerar las relaciones entre ellas en el transcurso del tiempo.

6.- Este es el momento de recurrir a los datos de las excavaciones arqueológicas que, en el caso de la Ciudad de México, resultan fundamentales para decirnos qué había debajo de cada una de las estructuras actuales, qué calles eran prehispánicas, cuáles eran antiguas acequias y qué elementos no existían en la primera mitad del siglo xvi. Por otro lado, la arqueología nos sirve para corroborar los datos que son el resultado del análisis urbano sobre la cartografía actual.

Un ejemplo palpable de esta función de los datos arqueológicos es la posibilidad de establecer los límites de la urbe castellana, ya que se encuentran zonas con niveles de ocupación prehispánica en tiempos en los que el contacto entre europeos y mexicas ya se había dado. Esto claramente nos arroja que se trata de barrios indios, mientras que en otras áreas surgen, dentro de una idéntica cronología, niveles completamente desocupados, lo que nos marca la existencia de espacios vacíos defensivos (típicos del urbanismo islámico) que envolvían la ciudad castellana y separaban a indios de peninsulares. En el caso de las excavaciones que se realizan en espacios que claramente están dentro de la Ciudad de México, nos encontramos con niveles donde conviven las cerámicas hispanas con las prehispánicas, especialmente Azteca IV y Azteca V.

7.- Finalmente, los datos obtenidos del análisis urbanístico requieren ser plasmados en un SIG que contribuya a visualizar, manejar y relacionar la información.

La metodología del análisis urbanístico que aquí estoy refiriendo procede, en gran medida, de los estudios de Jean Pierre Lavedan, quien en 1926 postuló la ley de persistencia del plano9. Esta teoría esboza la persistencia de las líneas y de los espacios urbanos entre la actualidad y el tiempo de su creación en sentido esencial.

En la escuela de Lavedan podemos encontrar también a Pierre Pinot. Este teórico plantea que es viable la ejecución de un examen gráfico de la ciudad que consigue, incluso, ser aprovechado como herramienta de reconstrucción de esta. Defiende que, para analizar una urbe, es necesario localizar un orden en el desorden o cierta regularidad dentro de las irregularidades ${ }^{10}$.

\footnotetext{
${ }^{9}$ Lavedan, Pierre, “Qu'est-ce que l'urbanisme?”, en Annales du Midi, 39 (1926), p. 91.

${ }^{10}$ Pinon, Pierre, "La transición desde la ciudad antigua a la ciudad medieval. Permanencia y transformación de los tejidos urbanos en el Mediterráneo Oriental", en Passini, Jean (coord.), La ciudad medieval: de la casa al tejido urbano, Cuenca, Universidad de Castilla-La Mancha, 2001, p. 181.
} 
La ciudad es una entidad que muta y se adecúa a las exigencias de la sociedad que en ella reside. Algunos de los fragmentos de su trama pervivirán, mientras que otros cambiarán o serán disueltos. Sin embargo, no podemos olvidar que, cualquier modificación urbana viene con un alto coste ${ }^{11}$, por lo que es lícito presumir que estas transformaciones deben ser promovidas por potencias de gran magnitud; es decir, una gran necesidad, una gran costumbre, una gran voluntad de alarde del poder, etc.

Por otra parte, en los análisis urbanísticos hay que tener en cuenta que los espacios que comúnmente se consideran vacíos pueden haber cumplido una función especial. De igual manera habrá que hacer con los diversos espacios, ya que la correcta identificación de estos debe llevarse a cabo por medio no solo de la excavación y del análisis de paramentos ${ }^{12}$, sino también por medio del análisis morfológico del plano actual.

\section{Caso práctico del análisis arqueológico-urbanístico de la Ciudad de México: el límite norte de la ciudad castellana}

Para comprender los alcances y la utilidad de la metodología que propongo, es interesante y, quizás, necesario proporcionar un ejemplo claro de su funcionamiento. El caso del límite norte de la primera Ciudad de México es decididamente polémico. Cuando señalo esto, hago referencia a las tentativas de estudiosos como Justino Fernández ${ }^{13}$ y Manuel Toussaint ${ }^{14}$ por arrojar luz sobre esta frontera de la urbe cortesiana. La primera Ciudad de México, que fue construida tras la caída de la capital mexica en manos de Hernán Cortés fue una ciudad que, según las fuentes históricas ${ }^{15}$, tuvo una morfología peculiar: la urbe construida y habitada por las autoridades conquistadoras se encontraba en el centro del islote - anterior centro ceremonial-, rodeada por cuatro barrios indígenas que ya existían en tiempos prehispánicos, pero que mantuvieron continuidad una vez que se establecieron las nuevas autoridades tras la conquista.

Así, la primera Ciudad de México se encontraba en medio de un lago y se conformaba como una urbe mixta que tenía, por un lado, una enorme cantidad de población indígena dentro del islote, pero que, en su centro, contenía un núcleo urbano castellano que fue habitado por

\footnotetext{
${ }^{11}$ Salvatierra, Vicente, "La reconstrucción del parcelario de las ciudades andalusíes. Las aportaciones de la documentación contemporánea", en Passini, Jean (coord.), La ciudad medieval: de la casa al tejido urbano, Cuenca, Universidad de Castilla-La Mancha, 2001, p. 35.

${ }^{12}$ Ibídem, p. 48.

${ }^{13}$ Fernández, Justino, Planos de la ciudad de México, México, Instituto de Investigaciones Estéticas, UNAM, 1940, p. 58.

${ }^{14}$ Toussaint, Manuel, Planos de la ciudad de México, México, Instituto de Investigaciones Estéticas, UNAM, p. 96.

${ }^{15}$ López de Gómara, Francisco, Historia de la conquista de México, México, Porrúa, 2006 [1552], p. 227.
} 
las autoridades de la ciudad, conocido como "la Traza". Los límites de esta porción urbana han sido un problema constante para el urbanismo, cuyas aproximaciones no han sido del todo satisfactorias, ya que la información recopilada ha sido insuficiente.

El problema específico del límite norte de la Ciudad de México como caso de estudio resulta apasionante desde el punto de vista metodológico. Puede resumirse en los siguientes puntos:

1.- El límite norte de la Traza puede establecerse alternativamente en las siguientes calles:

a) República del Perú con su continuación por la calle del Apartado y la calle Peña y Peña en su trayecto hacia el oriente de la ciudad ${ }^{16}$.

b) República de Bolivia y su continuación por la calle José Joaquín Herrera de poniente a oriente.

c) República de Colombia con su continuación hacia el poniente de la ciudad en la calle Ana María del Toro Lazarín.

2.- Los problemas fundamentales que encontramos en este aspecto tienen que ver con que las fuentes históricas nos son claras y nos sugieren que la calle República del Perú es una acequia antigua que sirve como buena opción para el trazado de dicho límite.

3.- Cuando aplicamos una metodología interdisciplinar que utiliza las fuentes históricas, el análisis arquitectónico, el análisis urbanístico, el análisis cartográfico antiguo y los

Sistemas de Información Geográfica, los elementos que no cuadran para el establecimiento del límite salen a la luz.

Se debe tomar en cuenta que los límites de la Traza tuvieron que quedar muy bien definidos en un primer momento, ya que la ciudad paleohispánica estaba totalmente rodeada de población indígena que no tenía el derecho de establecerse dentro de la Traza.

El límite poniente de la ciudad es el que ha quedado definido con mayor claridad, ya que todos los investigadores que tratan el tema han propuesto la calle Lázaro Cárdenas como límite oeste de la Traza. Esta calle tiene un diseño que va en línea recta y que frecuentemente se sugiere que se extiende de norte a sur. Bajo un análisis más minucioso, puede notarse, dada la orientación de la ciudad, que la calle va, en realidad, desde el suroeste hacia el noreste. Desde su origen prehispánico, la ciudad no está exactamente orientada hacia los puntos cardinales, como se ha pretendido en análisis anteriores, sino que el eje de la calle está desviado seis grados hacia el noreste. Sin embargo, es verdad que el trazado de esta vía aparece como perfectamente rectilíneo, cosa que podría hacernos dudar de su trazado antiguo. Sin embargo, la calle aparece en todas las cartografías con las que contamos desde el mapa de Uppsala hasta nuestros días con la misma morfología, orientación y como límite de la ciudad.

En el mapa de Uppsala ${ }^{17}$ la calle Lázaro Cárdenas tiene una doble disposición, ya que en la primera mitad de sur a norte sale representada como una calle común y corriente, y en la

\footnotetext{
${ }^{16}$ A partir de ahora solo llamaré al trazado oriente-poniente de estas tres calles República de Perú.

${ }^{17}$ Interpretación del plano de Uppsala (Tussaint). Toussaint, Manuel, Planos de la ciudad... op. cit., p. 137.
} 
segunda mitad, desde la calzada México-Tacuba hasta llegar a Tlatelolco, parece tener forma de acequia o, por lo menos, la de una vía mixta que permitiera la circulación de canoas al igual que de personas a pie. Es factible que la vía llevara un acueducto que suministrara agua a Tlatelolco, ya que ahí aparece una alberca de la que probablemente la población de Santiago Tlatelolco se abastecía.

Dentro de los diversos planos ulteriores al mapa de Uppsala, la actual calle Lázaro Cárdenas aparece de manera consistente, hasta que su parte mixta desaparece para adoptar la morfología que conocemos.

En cuanto al límite norte de la ciudad, hemos ya establecido sus condiciones de determinación ambigua y que existen, por lo menos, tres posibles calles que se corresponden con él. Hemos mencionado también que la primera de ellas es la calle República del Perú y su continuación hacia el este llamada calle del Apartado, siendo esta una muy buena posibilidad, ya que su trazado se corresponde con el de una acequia que corría por este mismo lugar y que podría representar un límite natural de la Traza. No obstante, resulta que la acequia pasaba justamente por detrás del convento y la iglesia de Santo Domingo, circunstancia que hubiese permitido que dicho convento quedase dentro del espacio castellano junto con la iglesia de San Sebastián, parroquia de indios, en la esquina entre la actual calle Rodríguez Peña y José Joaquín Herrera, situación que no hubiese sido permitida.

Figura 1: Parroquia de San Sebastián y trazado de calle República del Perú.

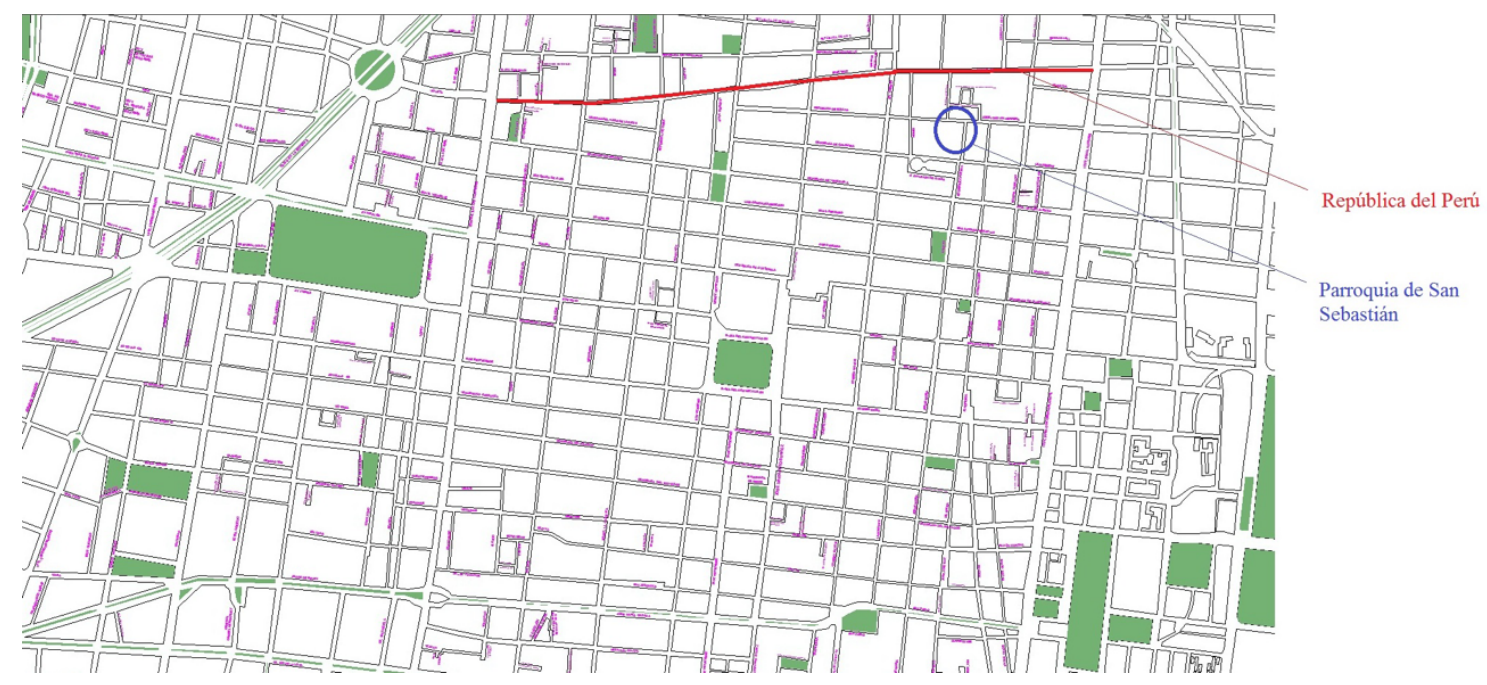

Fuente: Plano generado por el autor a partir de un shapefile de acceso abierto proporcionado por la Delegación Cuauhtémoc y utilizando el programa ArcGIS versión 10.3.

Al desechar la posibilidad de que la calle República del Perú fuera el límite norte de la Traza, he comenzado a sopesar la posibilidad de que la calle situada de forma paralela, hacia el sur, a República del Perú pudiera ser el verdadero límite. Esta calle lleva el nombre de República de Bolivia y presenta un buen trazado, excepto porque parte un trozo del convento de Santo 
Domingo, aunque considero que esta calle debió unirse a la acequia de la actual República de Perú a la altura de la calle Allende.

Figura 2: Trazado de calle República de Bolivia como posible límite norte de la Traza.

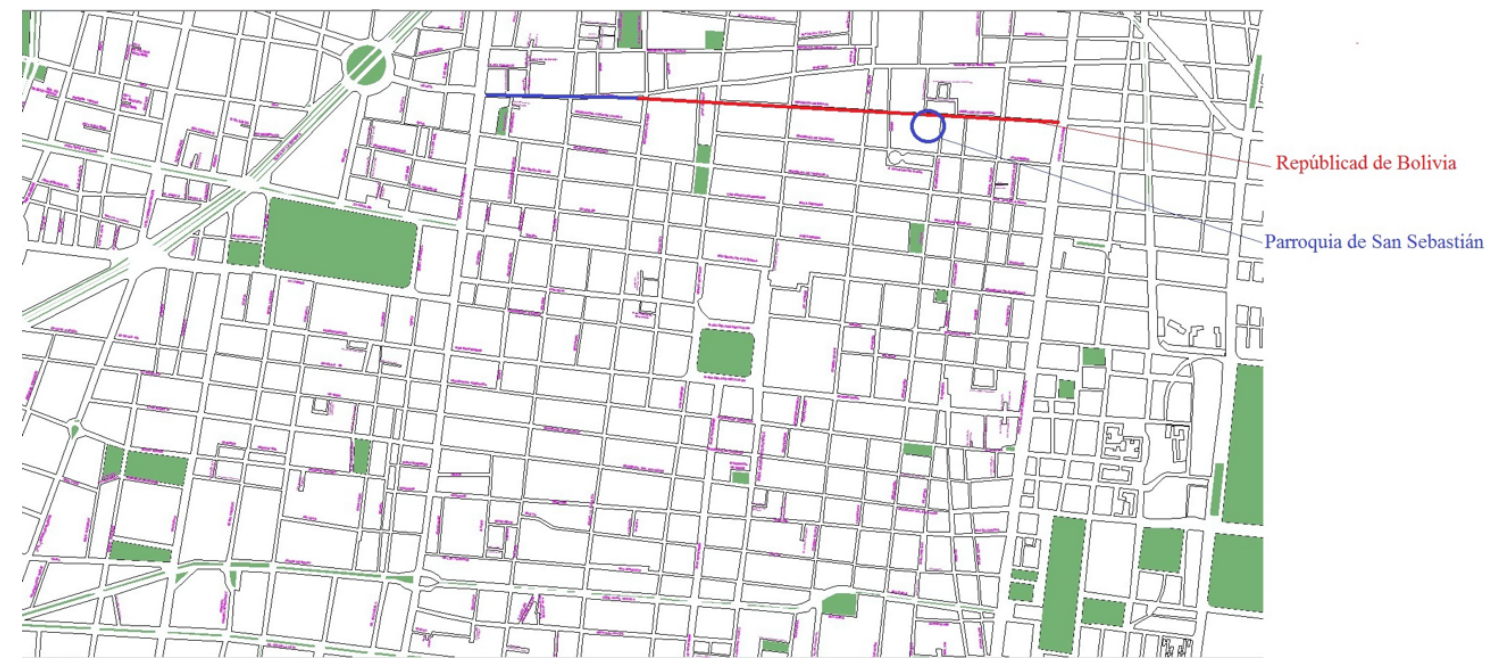

Fuente: Plano generado por el autor a partir de un shapefile de acceso abierto proporcionado por la Delegación Cuauhtémoc y utilizando el programa ArcGIS versión 10.3.

El verdadero inconveniente que presenta la teoría de la calle República de Bolivia como límite norte de la Traza es que, una vez más, la parroquia de San Sebastián quedaría dentro de la Traza. Sin embargo, hay un cambio fundamental: el templo está orientado con el altar mayor en dirección sur por lo que los visitantes podrían entrar desde un punto que se halla fuera de la Traza y, en este caso, la ciudad española no sostendría ninguna relación con la parroquia ni con los visitantes de esta.

Figura 3: Orientación de la parroquia de San Sebastián.

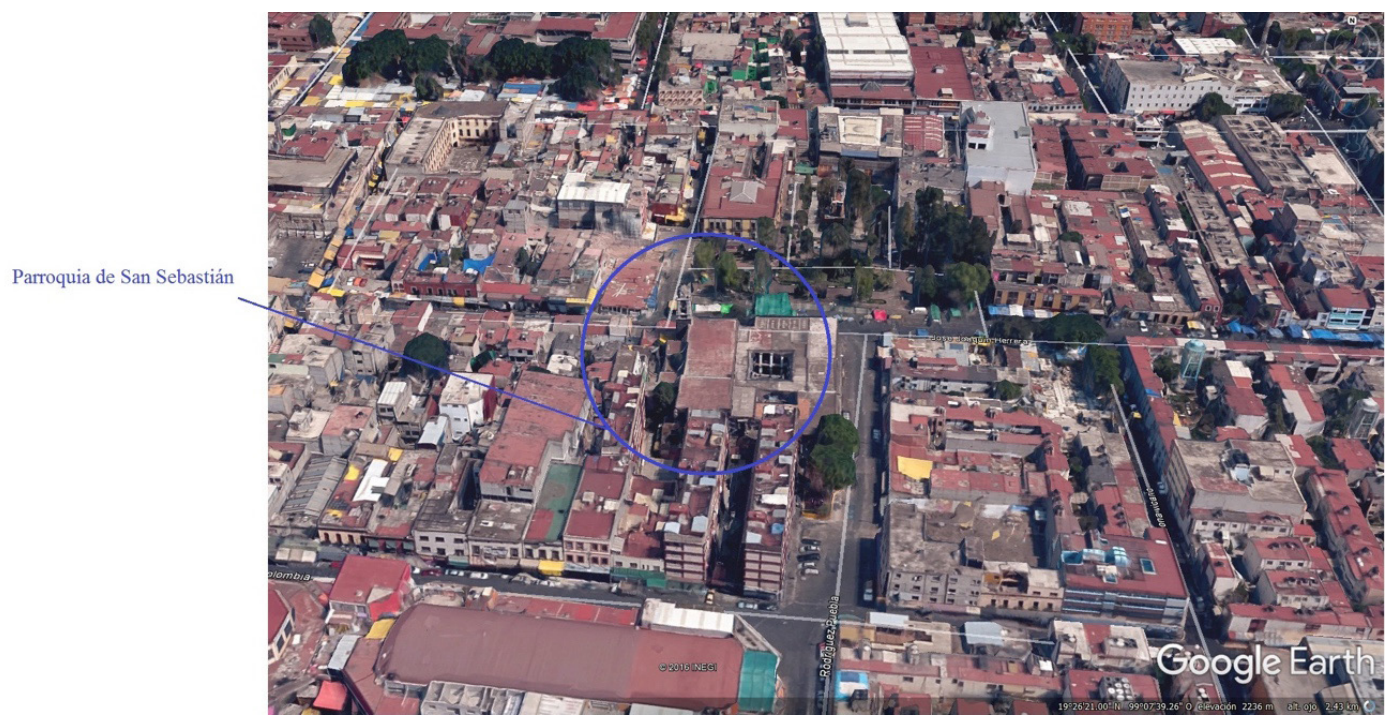

Fuente: Plano generado por el autor a partir de un shapefile de acceso abierto proporcionado por la Delegación Cuauhtémoc y utilizando el programa ArcGIS versión 10.3. 
La tercera teoría del límite norte establece que podría haber transcurrido por la calle Ana María R. Del Toro Lazarín y República de Colombia. Este trazado tiene como inconveniente que partiría por la mitad la actual iglesia de Santo Domingo, por lo que habría que constatar que dicha iglesia no existiera a principios del siglo xvi. De ser así, el trazado resultaría muy conveniente porque sitúa la parroquia de indios fuera de la Traza de manera absoluta.

Figura 4: Trazado de la calle República de Colombia.

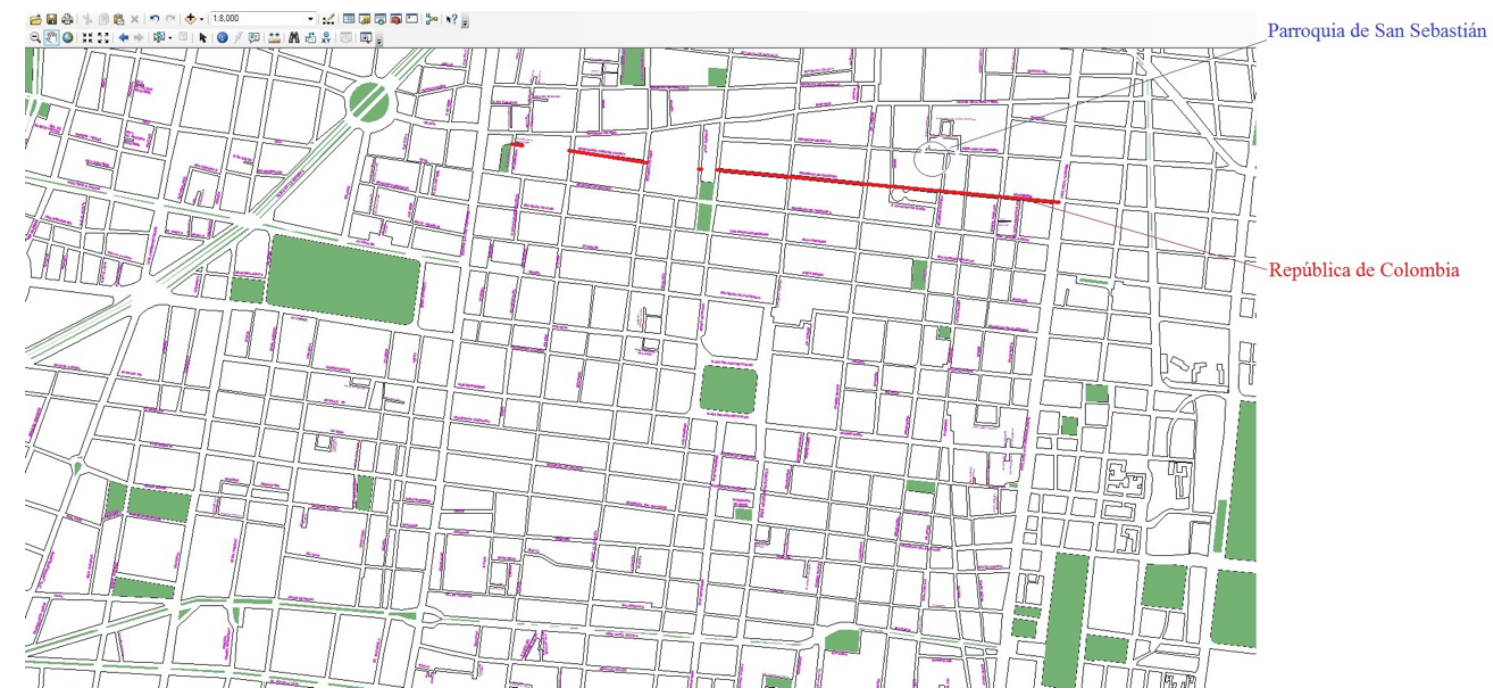

Fuente: Plano generado por el autor a partir de un shapefile de acceso abierto proporcionado por la Delegación Cuauhtémoc y utilizando el programa ArcGIS versión 10.3.

El límite que figura en el mapa de Uppsala resulta confuso, pues en él aparece la acequia que, por su trazado cercano a la actual calle Lázaro Cárdenas, podría ser aquella que pasaba por la calle República del Perú. Sin embargo, no nos resulta lógico que este sea el límite de las viviendas que se encuentran dentro de la Traza, ya que parece haber un cierto espacio vacío entre la acequia y las viviendas que se encuentran más al sur.

No obstante, es importante mencionar que, en dicho mapa, la calle República de Argentina aparece como una calzada o eje principal de la ciudad cuya terminación es justamente la acequia de la actual República del Perú. Esto nos puede sugerir que la acequia sí cumplía la función de límite de la Traza aunque las viviendas no llegasen hasta este punto.

En cuanto a la representación de la parroquia de San Sebastián, en el mapa de Uppsala resulta sorprendente el hecho de que la parroquia aparece al norte de la acequia que considerábamos parte de la calle del Apartado que es, a su vez, continuación de la calle República del Perú.

Por este motivo podemos considerar que la acequia que pensábamos que pasaba por República del Perú y que continuaba por calle del Apartado tenía, en realidad, un trazado diferente que podría pasar primero por República del Perú y que, después, continuara por la calle República de Bolivia o de Colombia. Uno de los elementos que encontramos en el mapa de Uppsala que nos ayuda a resolver esta incógnita es la forma de la plaza de Santo Domingo, 
ya que la manzana actual es un rectángulo cuyo lado más largo va de norte a sur. Sin embargo, en la representación del mapa de Uppsala el lado más largo de la plaza iba de oriente a poniente. Esto podría insinuarnos que el límite norte de la antigua plaza de Santo Domingo se encontrara más al sur de lo que se encuentra la calle República del Perú.

Figura 5: Límite norte en el Mapa de Uppsala.

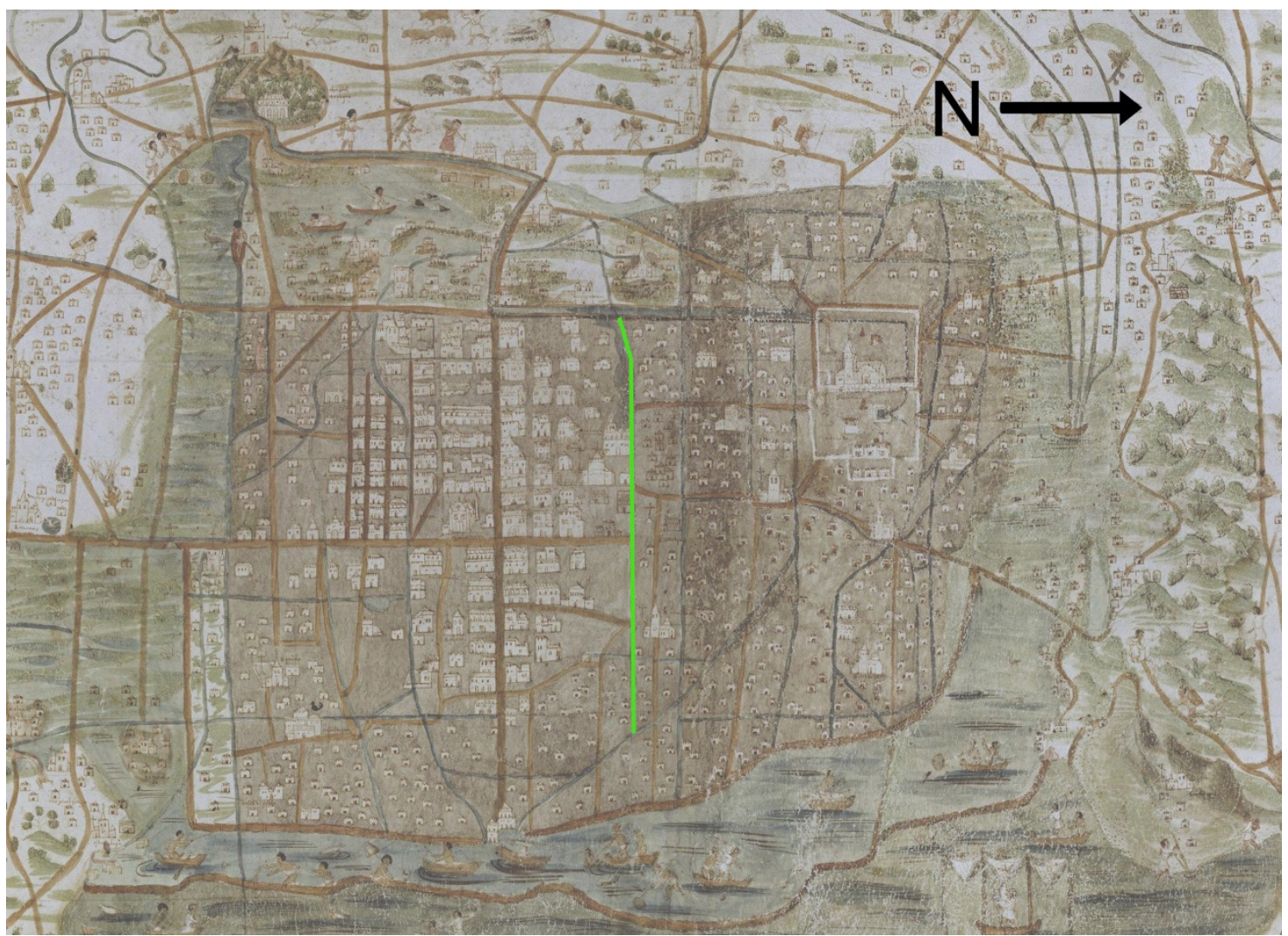

Fuente: Toussaint, Manuel, Planos de la ciudad de México, México, Instituto de Investigaciones Estéticas, UNAM, p. 137.

La teoría que me parece más factible sobre el límite norte de la Traza es que la acequia que aparece en el mapa de Uppsala, la cual puede ser confundida constantemente con la calle República del Perú, fuera en realidad la calle de República de Colombia. Esto lo propongo por la situación en la que aparece en el mapa de Uppsala la parroquia de San Sebastián. En este mismo sentido la calle que pasa por delante de la puerta de la parroquia tendría que corresponder a la actual calle República de Bolivia con su continuación llamada José Joaquín Herrera, que es precisamente donde se encuentra la puerta de la parroquia de San Sebastián. La acequia que aparece al norte de la parroquia tendría que ser República de Perú. 
Figura 6: Parroquia de San Sebastián en el Mapa de Uppsala.

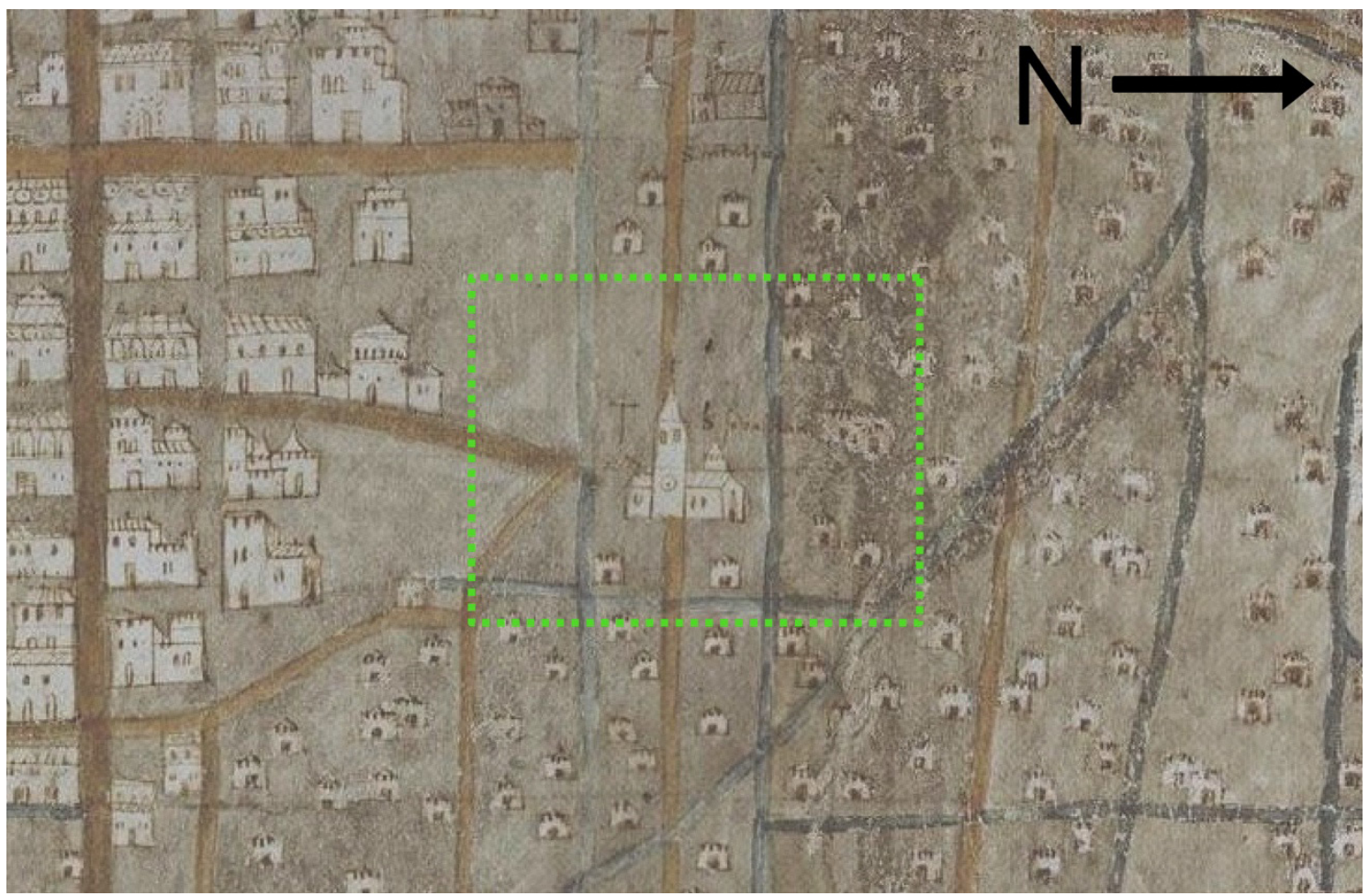

Fuente: Toussaint, Manuel, Planos de la ciudad de México, México, Instituto de Investigaciones Estéticas, UNAM, p. 137.

El mapa de Uppsala coincide en gran parte con las calles actuales que he mencionado anteriormente y es cierto que la acequia que pasaba por detrás del convento de Santo Domingo aparece como el límite de facto de la ciudad. Sin embargo, el espacio al sur del límite norte parece ser un espacio vacío que se podría corresponder a una táctica militar parecida a la que los gobernantes musulmanes aplicaban en las ciudades peninsulares como Badajoz y Toledo al dejar un espacio vacío frente a la alcazaba como medida defensiva para poder tener "a tiro" al enemigo en caso de ser tomada la ciudad y quedar la alcazaba como último reducto defensivo del poder local ${ }^{18}$.

Dicha zona neutral, en este caso, parece ser un espacio vacío que servía para poder ver al atacante a distancia y, así, prever su aproximación, hecho a la usanza del urbanismo islámico medieval.

Con relación a este punto George Kubler nos dice:

Por orden del virrey, todas las viviendas de los indígenas que estuvieran a la distancia de un tiro de pistola de la ciudad deberían ser removidas. Cuando la

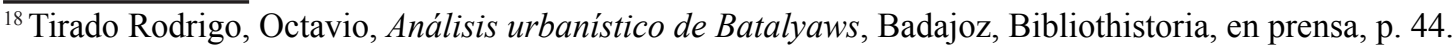


movilización de los indios se concluyó, el distrito fue derribado y usado como zona neutral. ${ }^{19}$

Figura 7: Plano con las posibilidades que he mencionado para el límite norte en la actualidad.

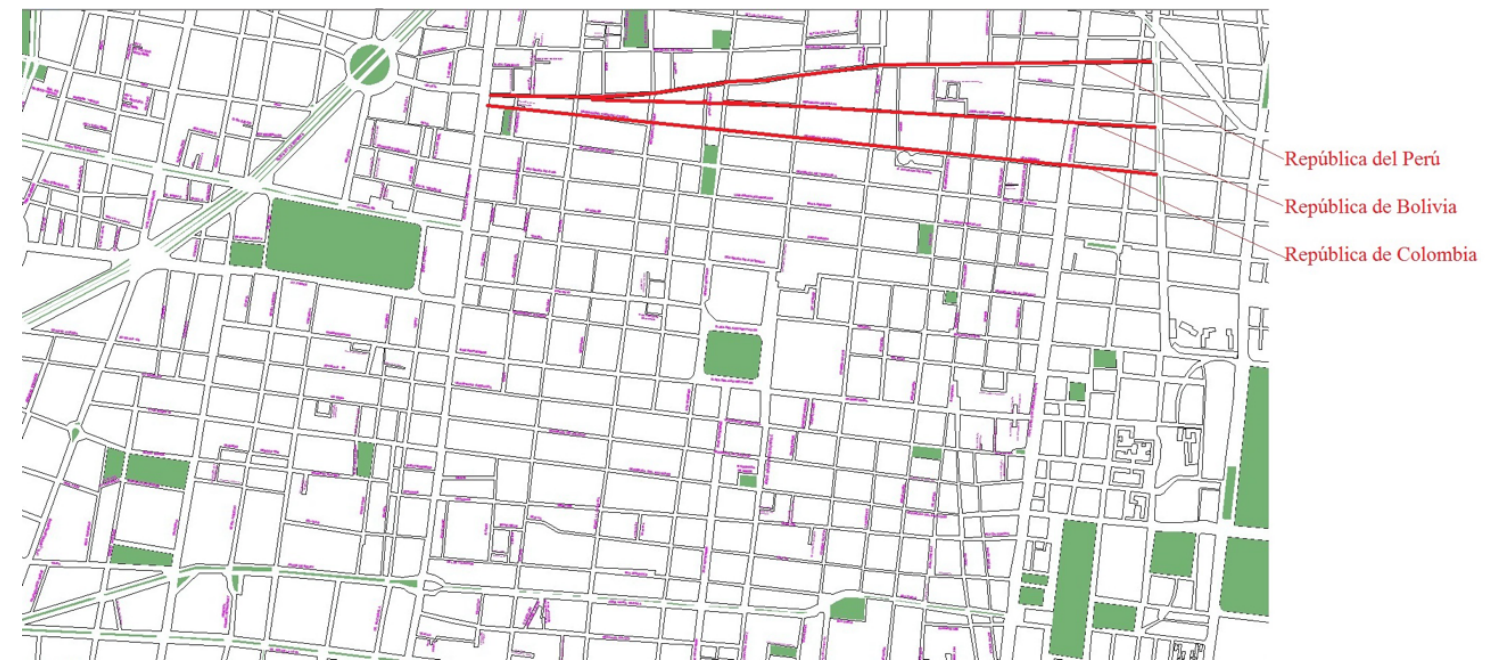

Fuente: Plano generado por el autor a partir de un shapefile de acceso abierto proporcionado por la Delegación Cuauhtémoc y utilizando el programa ArcGIS versión 10.3.

\section{Conclusiones}

La metodología interdisciplinar expuesta al comienzo de este artículo tiene la intención de arrojar un estudio integrado en el que los análisis de fuentes directas, indirectas y de los estudios urbanísticos que se han hecho sobre la ciudad, conjugados con el estudio de las cartografías tanto antiguas como actuales y con el de los datos arqueológicos tanto de las excavaciones realizadas como de las cerámicas encontradas, arrojarán luz sobre la estructura y la evolución de un asentamiento, contribuyendo a distinguir de manera más clara ciertos elementos urbanos que pudieron o no haber sido contemporáneos y, así, volviendo su recreación en un tiempo concreto mucho más precisa.

En cuanto a la importancia del análisis arqueológico en específico, este nos proveerá de datos científicos y medibles que contribuirán a corroborar los datos históricos que, en muchas ocasiones, tienden a exagerar o a alterar en diferentes grados las noticias que nos aportan, ya que la intención de dichos textos, en la mayor parte de los casos, era diferente a la nuestra y

$\overline{{ }^{19} \text { Kubler, George, }}$ Arquitecturas Mexicanas del... op.cit., p. 125. 
estaban imbuidos de elementos retóricos que más que informar pretenden conmover el ánimo del receptor del texto, sobre todo en el caso de los textos antiguos.

El ejemplo de aplicación de esta metodología que presentamos en el transcurso de este artículo (aunque los hay de muchas otras índoles), nos demuestra que resulta bastante útil en la delimitación de la ciudad en tiempos antiguos. Como sabemos, la mayor parte de las urbes antiguas fueron de diferente tamaño que la ciudad que se encuentra sobre ellas hoy en día y una metodología interdisciplinar, que tome en consideración distintos aspectos urbanos bajo puntos de vista diferentes, puede resultar muy esclarecedora. Además, esta misma metodología puede dar cuenta de procesos de aculturación, si es que la ciudad que nos concierne - como es el caso de la Ciudad de México del siglo xvi - los sufrió durante el momento que estamos estudiando. También puede contribuir a diferenciar tipologías y clases sociales y sus interacciones (con la integración del análisis cerámico, sus tipologías, y su grado de improvisación).

Existen, pues, infinidad de aplicaciones de las metodologías que he mencionado, ya sea por separado o integradas en un todo. Esto sin tomar en cuenta las diversas disciplinas que pueden todavía integrarse (como la semiología, que contribuiría en el estudio de la construcción de signos y proliferación de significados en la disposición de los elementos urbanos) y ser utilizadas para complementar los estudios de la ciudad, que lejos de confundir o empañar la visión que tenemos de la urbe antigua, arrojan luz sobre dicho objeto de estudio y nos acercan, todas ellas, a una realidad más compleja. 